Assessing the Impact of Indexing Performance Measure Codes on the Perceived Value of EPC Reports to Health Systems

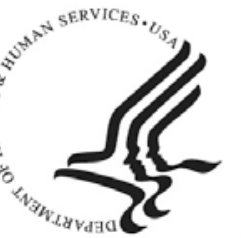




\title{
Assessing the Impact of Indexing Performance Measure Codes on the Perceived Value of EPC Reports to Health Systems
}

\author{
Prepared for: \\ Agency for Healthcare Research and Quality \\ U.S. Department of Health and Human Services \\ 5600 Fishers Lane \\ Rockville, MD 20857 \\ www.ahrq.gov
}

Contract No. 290-2015-00012-I

Prepared by:

University of Connecticut Evidence-based Practice Center

Hartford, CT

Investigators:

C. Michael White, Pharm.D., FCP, FCCP

Craig I. Coleman, Pharm.D.

Kimberly Jackman, Pharm.D.

AHRQ Publication No. 18-EHC022-EF

September 2018 


\section{Key Messages}

- Purpose: To discern if the inclusion of a hyperlinked quality measure index (QMI) enhances the usability of EPC reports.

- Findings: The use of QMI is considered novel, increases the speed at which quality measure information from an EPC report can be retrieved, and increases the likelihood that EPC reports will be used by health systems.

- Lessons Learned for EPC Program: There are small enhancements to our current reports which can improve the usability and likeability of reports and including health systems in the process of determining the most promising enhancements which increases the value of the final product created.

- Utility for Health Systems: QMI increased efficiency of determining whether quality measure information in an EPC report is relevant to their needs. 
This report is based on research conducted by the University of Connecticut Evidence-based Practice Center (EPC) under contract to the Agency for Healthcare Research and Quality (AHRQ), Rockville, MD (Contract No. 290-2015-00012-I). The findings and conclusions in this document are those of the authors, who are responsible for its contents; the findings and conclusions do not necessarily represent the views of AHRQ. Therefore, no statement in this report should be construed as an official position of AHRQ or of the U.S. Department of Health and Human Services.

\section{None of the investigators have any affiliations or financial involvement that conflicts with the material presented in this report.}

The information in this report is intended to help health care decisionmakers—patients and clinicians, health system leaders, and policymakers, among others-make well-informed decisions and thereby improve the quality of health care services. This report is not intended to be a substitute for the application of clinical judgment. Anyone who makes decisions concerning the provision of clinical care should consider this report in the same way as any medical reference and in conjunction with all other pertinent information, i.e., in the context of available resources and circumstances presented by individual patients.

This report is made available to the public under the terms of a licensing agreement between the author and the Agency for Healthcare Research and Quality. This report may be used and reprinted without permission except those copyrighted materials that are clearly noted in the report. Further reproduction of those copyrighted materials is prohibited without the express permission of copyright holders.

AHRQ or U.S. Department of Health and Human Services endorsement of any derivative products that may be developed from this report, such as clinical practice guidelines, other quality enhancement tools, or reimbursement or coverage policies may not be stated or implied.

Persons using assistive technology may not be able to fully access information in this report. For assistance contact EPC@ahrq.hhs.gov.

Suggested citation: White CM, Coleman CI, Jackman K. Assessing the Impact of Indexing Performance Measure Codes on the Perceived Value of EPC Reports to Health Systems.

Methods Research Report. (Prepared by the University of Connecticut Evidence-based Practice Center under Contract No. 290-2015-00012-I.) AHRQ Publication No. 18-EHC022-EF. Rockville, MD: Agency for Healthcare Research and Quality. September 2018. Posted final reports are located on the Effective Health Care Program search page. DOI: https://doi.org/10.23970/AHRQEPCMETHENGAGEASSESS. 


\section{Preface}

The Agency for Healthcare Research and Quality (AHRQ), through its Evidence-based Practice Centers (EPCs), sponsors the development of evidence reports and technology assessments to assist public- and private-sector organizations in their efforts to improve the quality of health care in the United States. The reports and assessments provide organizations with comprehensive, science-based information on common, costly medical conditions and new health care technologies and strategies. The EPCs systematically review the relevant scientific literature on topics assigned to them by AHRQ and conduct additional analyses when appropriate prior to developing their reports and assessments.

To improve the scientific rigor of these evidence reports, AHRQ supports empiric research by the EPCs to help understand or improve complex methodologic issues in systematic reviews. These methods research projects are intended to contribute to the research base in and be used to improve the science of systematic reviews. They are not intended to be guidance to the EPC program, although they may be considered by EPCs along with other scientific research when determining EPC program methods guidance.

AHRQ expects that the EPC evidence reports and technology assessments will inform individual health plans, providers, and purchasers and the health care system as a whole by providing important information to help improve health care quality. The reports undergo peer review prior to their release as a final report.

We welcome comments on this Methods Research Project. They may be sent by mail to the Task Order Officer named below at: Agency for Healthcare Research and Quality, 5600 Fishers Lane Rockville, MD 20857, or by e-mail to epc@ahrq.hhs.gov.

Gopal Khanna

Director

Agency for Healthcare Research and Quality

Stephanie Chang, M.D., M.P.H.

Director

Evidence-based Practice Center Program

Center for Evidence and Practice Improvement

Agency for Healthcare Research and Quality
Arlene Bierman, M.D., M.S.

Director

Center for Evidence and Practice Improvement

Agency for Healthcare Research and Quality

Lionel L. Bañez, M.D.

Medical Officer/Task Order Officer

Center for Evidence and Practice

Improvement

Agency for Healthcare Research and Quality 


\section{Acknowledgments}

The authors gratefully acknowledge the following individuals for their contributions to this project:

\section{Key Informants}

The EPC consulted several Key Informants who represent the end-users of the research, health systems. The EPC sought the Key Informant input on the priority areas for research and synthesis. Key Informants are not involved in the analysis of the evidence or the writing of the report. Therefore, in the end, study questions, design, methodological approaches, and/or conclusions do not necessarily represent the views of individual Key Informants.

Key Informants must disclose any financial conflicts of interest greater than $\$ 5,000$ and any other relevant business or professional conflicts of interest. Because of their role as end-users, individuals with potential conflicts may be retained. The TOO and the EPC work to balance, manage, or mitigate any conflicts of interest.

The list of Key Informants who provided input to this report follows:

Christina Polomoff, Pharm.D.

Hartford Healthcare Integrated Care Partners

Wethersfield, CT

Michelle L DeLayo, M.S., APRN, ACNP-BC

University of Connecticut Health/John Dempsey Hospital

Farmington, CT

George Cheely, M.D.

Duke University Health System

Raleigh-Durham, NC

Alison C. Weidner, M.D.

Duke University Health System

Raleigh-Durham, NC

Thomas A. Owens, M.D.

Duke University Health System

Raleigh-Durham, NC

Jonathon G. Bae, M.D.

Duke University Health System

Raleigh-Durham, NC 


\section{Assessing the Impact of Indexing Performance Measure Codes on the Perceived Value of EPC Reports to Health Systems}

\section{Structured Abstract}

Background. EPC reports are lengthy and difficult for health systems to navigate which could impede their use by these key stakeholders. In this project, we created a report enhancement, the addition of a quality measure index, to allow health systems to circumvent the minutia and more efficiently access information relevant to their needs.

Methods. We created and embedded two additional tables in a previously completed EPC report. The first identified quality measures covered by the report with descriptive information. The second contained page numbers in the report's executive summary where those quality measures are addressed with hyperlinks to immediately navigate to those pages. We received feedback from health-system representatives, enhanced our tables, and created an exercise with two health-system targeted scenarios. We then had representatives from two different types of health systems (moderate-sized community and small academic but rural) complete the exercises and answer 3 questions regarding their current use of EPC reports, the ease of using the enhanced tables, and the likelihood of using EPC reports with enhanced tables such as these.

Results. Our initial enhanced quality measure tables were well regarded by four representatives of a large academic health system. They provided suggestions for improvement as did members of AHRQ. We incorporated them in revised quality measure tables. We piloted the proposed exercise with two pharmacy students before sending it to two health-system representatives. Correct answers were found in both scenarios. It took our health-system participants 68 to 82 percent less time to find quality measure information when the hyperlinked quality measure indexing tables were available. In the qualitative portion of the assessment, both health-system representatives stated they rarely used EPC reports, they both found the quality measure index tables very easy to use, and one was somewhat likely and the other very likely to use the reports in the future if they had enhanced quality measure tables like these available.

Discussion/Conclusion. We identified a unique concept that can allow current EPC reports be more user friendly to health systems. Working in concert with representatives from different types of health systems, we were able to refine the quality measure indexed tables so that they were easier to understand and navigate and to enhance the efficiency of finding relevant information. Quality measure indexing is a promising and novel approach to enhance the usability of EPC reports for health systems. 


\section{Contents}

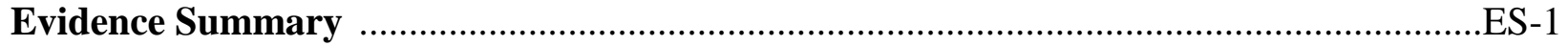

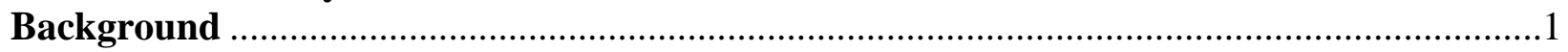

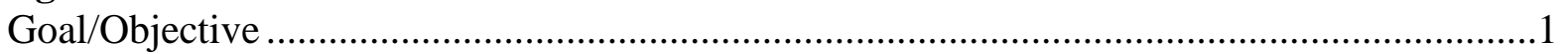

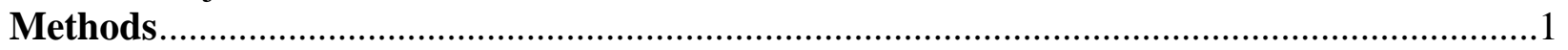

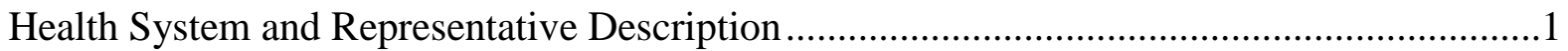

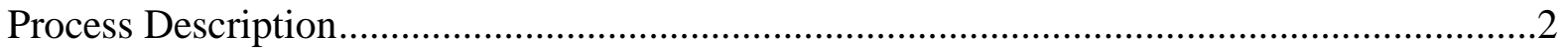

Evaluation Methods .....................................................................................................

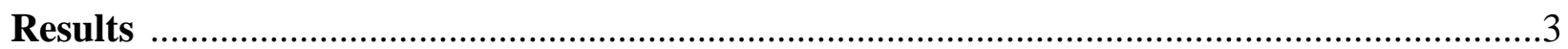

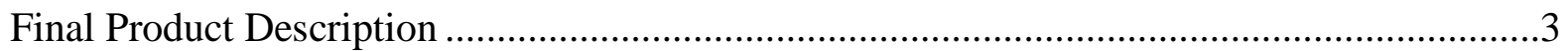

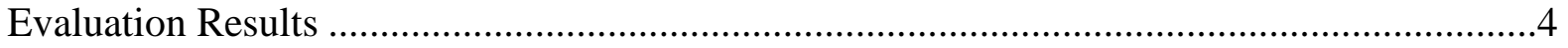

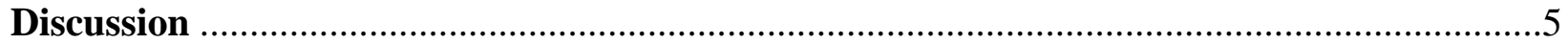

Utility and Application for Other Health Systems..........................................................5

Lessons Learned and Applicability for Other EPC Reports ............................................6

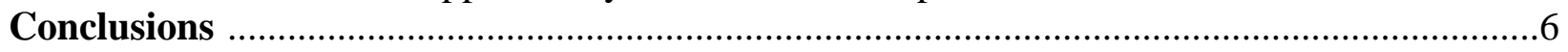

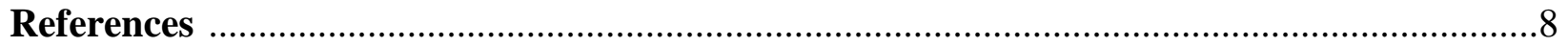

\section{Tables}

Table 1 . Time required to find quality measure information in the urinary incontinence report ....5

\section{Appendixes}

Appendix A. Sample Tables for EPC Reports with Exercise and Questions for Key Informants 


\section{Evidence Summary}

\section{Background}

In previous work, health-system representatives were less likely to use EPC reports than other sources of information because the reports were lengthy and it was difficult to devote sufficient time to determine if relevant information was available in a report and where to locate it. ${ }^{1}$ In this project we created a report enhancement, the addition of a quality measure index, to allow health systems to circumvent the minutia and more efficiently access information relevant to their needs.

\section{Methods}

We created and embedded two additional tables in a previously completed EPC report. The first identified measures covered by the report with descriptive information on the measures. The second table contained the pages in the reports executive summary where those quality measures are addressed and hyperlinks to immediately navigate to those pages. We received feedback from health-system representatives, revised our tables, and created an exercise with two health-system targeted scenarios. We then had representatives from two different types of health systems (moderate-sized community and small academic but rural) complete the exercises and answer three questions regarding their current use of EPC reports, the ease of using the enhanced tables, and the likelihood of using EPC reports with enhanced tables such as these. The first scenario is about National Quality Measure Clearinghouse (NQMC) \# 09644, adverse events associated with urinary incontinence, while the second scenario centers around NQMC \#09633, the role of behavioral therapy in urinary incontinence.

\section{Results}

Our initial enhanced quality measure tables were well regarded by four representatives of a large academic health system. They suggested that we could improve the usability of the second table by explicitly identifying the page numbers where the most relevant information on a quality measure could be found rather than listing them all and having the health-system users have to click and review each one to determine the best ones. We also received feedback from AHRQ about making the legends of the tables more explicit for readers to follow. We made the change requested by the health system representatives and AHRQ and then piloted the proposed exercise with a physician and two pharmacists in our research group before sending it to the two healthsystem representatives. Correct answers were found in both scenarios. It took our health-system participants 68 to 82 percent less time (on average 7.2 minutes less for both scenarios combined) to find quality measure information when the hyperlinked quality measure indexing tables were available (Table 1). In the qualitative portion of the assessment, both health-system representatives stated they rarely used EPC reports, they both found the quality measure index tables very easy to use, and one was somewhat likely and the other very likely to use the reports in the future if they had enhanced quality measure tables available. 
Table A. Time required to find quality measure information in the urinary incontinence report

\begin{tabular}{|l|l|l|l|l|}
\hline Participants & $\begin{array}{l}\text { Time to Find } \\
\text { Answer in } \\
\text { Scenario 1 } \\
\text { without } \\
\text { Enhancement }\end{array}$ & $\begin{array}{l}\text { Time to Find } \\
\text { Answer in } \\
\text { Scenario 1 } \\
\text { with } \\
\text { Enhancement }\end{array}$ & $\begin{array}{l}\text { Time to Find } \\
\text { Answer in } \\
\text { Scenario 2 } \\
\text { without } \\
\text { Enhancement }\end{array}$ & $\begin{array}{l}\text { Time to Find } \\
\text { Answer in } \\
\text { Scenario 2 } \\
\text { with } \\
\text { Enhancement }\end{array}$ \\
\hline \hline $\begin{array}{l}\text { Health-System } \\
\text { Representative } \\
\mathbf{1}\end{array}$ & $9 \mathrm{~min}$ & $0.75 \mathrm{~min}$ & $6 \mathrm{~min}$ & $0.5 \mathrm{~min}$ \\
\hline $\begin{array}{l}\text { Health-System } \\
\text { Representative } \\
\mathbf{2}\end{array}$ & $12 \mathrm{~min}$ & $3 \mathrm{~min}$ & $11 \mathrm{~min}$ & $5 \mathrm{~min}$ \\
\hline
\end{tabular}

Note: While the participants are described by name in the text, we maintain anonymity of responses.

\section{Discussion}

We identified a unique concept that can allow current EPC reports be more user friendly to health systems. Working in concert with representatives from different types of health systems, we were able to refine the quality measure indexed tables so that they were easier to understand and navigate as well as enhancing the efficiency of finding relevant information. When we tested this enhancement, the health-system end users of the reports had increased efficiency of finding information and liked the new index. They felt that the index could improve the chances that they would use EPC reports should indexes like this be included in the future. We looked at three different types of health systems but only a few people overall so we cannot be sure that these results are applicable to all health systems. In addition, the number and type of quality measures varies widely among different diseases states, patient populations, and interventions so some EPC reports may be more conducive to having quality measure indexing than others. Since the indexing requires in depth knowledge of the topic and the findings of the report, the EPCs themselves might be in the best position to do the indexing although consistent methods to locate, retrieve, vet, and link quality measures across different report types will have to be established.

\section{Conclusion}

Quality measure indexing is a promising and novel approach to enhance the usability of EPC reports for health systems. 


\section{References}

1. White CM, Sanders-Schmidler GD, Butler M, et al. Understanding health systems' use of and need for evidence to inform decisionmaking. Agency for Healthcare Research and Quality (US); 2017

Oct. Report 17(18)-EHC035-EF. Rockville, MD

PMID 29611913. 


\section{Background}

In Health System Working Group-2, a working group comprised of members of various EPCs and AHRQ, we spoke with prominent members of quality, safety, and process improvement within health systems about how they identify and use evidence. ${ }^{1}$ The participants stated that they benchmark performance on accepted quality measures to other health systems and if they are found to be below their reference group; seek out ways to address those weaknesses. This means that quality measures drive the desire for literature evidence that can inform process improvements in health systems. ${ }^{1}$

AHRQ has developed the National Quality Measures Clearinghouse (www.qualitymeasures.ahrq.gov) which facilitates health systems' ability to see the range of quality measures that prominent organizations have created for the purposes of benchmarking in a specific area. This facilitates the acquisition of quality measures but after they benchmark and identify measures which require process changes to improve, there is currently no ability to directly search for key questions in AHRQ EPC reports that address those measures. One place to search for literature evidence is the Effective Health Care Web site where visitors search for topics by: body locations/body systems, demographic groups, diagnosis and therapy, disorders and conditions, or health and wellness; as displayed on www.EffectiveHealthcare.ahrq.gov/health-topics/. If they perceive the title of the report to be of relevance, they will then read the executive summary to see if the key questions are relevant to their needs. We believe that the current process is slow, cumbersome, and a barrier to utilization of AHRQ reports by health systems.

We believe that allowing health systems to search www.EffectiveHealthcare.ahrq.gov-based EPC reports for quality measures covered by those reports and then be able to hyperlink directly to the pages within those reports to see the information germane to those quality measures would drive traffic to the website and enhance the efficiency of health systems seeking out evidence. A single EPC could go back through recent previous reports and index them or the onus could be on EPCs creating those reports to index them for quality measures. This would require an initial effort on the part of AHRQ and the EPCs. Unless health systems find the concept useful, such an expenditure would not be worthwhile.

\section{Goal/Objective}

Our objective was to create a successful process for establishing a quality measure index for EPC reports that can make it intuitive and efficient for personnel interested in quality or safety within health systems to find content relevant to their needs.

\section{Methods}

\section{Health System and Representative Description}

Duke University Health System is a world-class health care network dedicated to providing outstanding patient care, educating tomorrow's health care leaders, and discovering new and better ways to treat disease through biomedical research. Founded in 1998 to provide efficient, responsive care, the health system offers a full network of health services and encompasses three highly regarded hospitals - Duke University Hospital, Durham Regional Hospital and Duke Raleigh Hospital - physician practices, home hospice care and various support services at 
locations across North Carolina. According to U.S. News \& World Report, Duke University Hospital was ranked \#1 in North Carolina, and \#1 in the Raleigh-Durham region for the 17th consecutive year. Duke University Health System has approximately 17,520 full-time employees. The academic Duke University Medical Center has about 10,829 full-time employees. As the Southeast's preeminent health care provider, Duke University Health System attracted more than 68,000 inpatient stays and more than 2 million outpatient visits in FY17.

George Cheely, M.D. is the Program Director of Care Redesign at Duke University Health System.

Alison C. Weidner, M.D. is the Director of Care Redesign Informatics at Duke University Health System.

Thomas A. Owens, M.D. is the President of the Duke Medical Center.

Jonathon Gregory Bae, M.D. is Associate Chief Medical Officer for the Duke University Health System.

Hartford Healthcare is a major integrated health system. Hartford Healthcare's Integrated Care Partners is a physician-led, clinically integrated health care network that includes employed physicians and affiliated community physicians across Connecticut. They coordinate care between the six system hospitals (including an 800 bed hospital/level I trauma center), two behavioral health facilities, and three post-acute care entities. ICP serves approximately 200,000 attributed lives through various commercial value-based contracts and participates in a Medicare Shared Savings Accountable Care Organization program. Their scores for CMS quality measures place them in the top 20 percent of health systems.

Christina M Polomoff, Pharm.D. is the Population Health Clinical Pharmacist who uses data analytics to address quality and cost metrics related to prescribing practices. She uses multiple modalities to target high-modifiable medication risk patients including home-visitations, telephonic and e-consults drug therapy management.

University of Connecticut Health Center is a rural academic health system of 224 beds in the town of Farmington, CT. The University of Connecticut Health-System has made important strides in enhancing safety over the past 5 years and recently received three Top " $A$ " ratings for patient safety measures and is above the median ranking for patient safety by Consumer Reports.

Michelle L. DeLayo, MS, APRN, ACNP-BC is the Interim Director of Quality and Lead Quality Improvement Advanced Practice Registered Nurse for UConn Health which includes John-Dempsey Hospital and a practicing APRN in the health system.

\section{Process Description}

To create a mock quality measure index we utilized a draft AHRQ report conducted by the Brown EPC on Urinary Incontinence. We performed a comprehensive search of qualitymeasure-related websites in detail, including the Agency for Healthcare Research and Quality (AHRQ) National Quality Measure Clearinghouse (NQMC); National Quality Forum (NQF): Quality Positioning System (QPS); www.qualitynet.org; National Committee for Quality Assurance (NCQA); Healthcare Effectiveness Data and Information Set (HEDIS); Center for Medicare and Medicaid Services (CMS); CMS; The Joint Commission (TJC); the US Department of Health and Human Services (HHS) Measures Inventory; Institute of Medicine (IOM) and the Health Resources and Services Administration (HRSA) to identify all measures with relevance for the disease state (urinary incontinence). From this list, we went through the report and identified which quality measures were directly addressed or would inform an aspect of a quality measure. We created a table (see Appendix A, Table A-1) which had all of the 
applicable and linkable quality measures including a reference number for the report; the title or explanation of the measures; the agency or body that created them; whether they were process or outcome measures; whether they were used in reimbursement, national reporting, or accreditation decisions, and key questions from the report which touched on the measures. We then used these measures and created another table (see Appendix A, Table A-2) which had the quality measure number and the exact page number in the executive summary where that measure can be found. For each of the quality measures in the second table, we hyperlinked each identified page number so when it is clicked on, the reader is transported into the executive summary to the exact page and location on the page where the information could be found. We shared this mock report with health-system key informants from Duke University Health Systems. Using web conferencing, we walked them through the rationale for our mock product and the functionality for what we had created. After we received their feedback, we refined our quality measure indexed report and then shared it with internal research group members before sending it to health-system key informants from Hartford Healthcare and the University of Connecticut Health.

\section{Evaluation Methods}

In the first phase, we asked the key informants from Duke University Health System about their assessment of the importance of such a report enhancement, improvements that could be made, and whether such an enhancement to the report would increase their willingness to use EPC reports in their safety or quality improvement projects in their health system. Questions were qualitatively asked and responses were collected. As described above, these responses informed improvements in the quality measure index before we began second phase assessment.

In the second phase, we sent the enhanced EPC draft report on urinary incontinence with brief written instructions to our health-system participants from Hartford Healthcare and UConn Health. We also sent them two clinical scenario exercises to complete and a few questions to answer as included in Appendix A. A physician and two pharmacists within our research group (Yuani Roman, MD; Thomas Easow, BS Pharm, Pharm.D. Candidate; and Mariah McCann, BS Pharm, Pharm.D. Candidate) piloted these scenarios before they were provided to our healthsystem representatives. The format (sending the report with minimal instructions on the enhancement and how it works) was done to assess whether people could use the legends of the two tables we created and intuitively determine how to use it. The clinical scenario exercises were assessed using a "before and after" method using time as the outcome of interest. Does it take less time and how much less time does it take to find specific quality measure informing data in an EPC report if a quality measure index can be accessed? There is a Likert scale and the likeability and usability of the quality measure index were assessed via these questions.

\section{Results}

\section{Final Product Description}

After the first phase feedback from the key informants at Duke University Health System, our TOO, and our multi-EPC working group, we revised our second quality measure index table to bold the page numbers where the key questions would best be addressed or where the density of information germane to that key question would reside. We also added information to the legend to make navigating the tables and the hyperlinks more intuitive. It took approximately 55 
hours to find and vet the quality measure addressed in the report, determine where the quality measures were addressed in the manuscript, and to create the tables with the bookmarking and hyperlinking functions. We believe that if we knew the topic, were familiar with the report, and applied the streamlined process we ultimately went through, we would have been able to create these two enhanced tables (Appendix A) in 30 hours.

\section{Evaluation Results}

In the phase one assessment, the key informants from the Duke University Health System, a large academic health system, were scheduled for one-hour conference calls with the EPC and AHRQ members of our working group. Approximately 20 minutes of each call was devoted to the quality measure index innovation. During the call they were told about the rationale for the quality measure indexing of reports and were shown a mock-up of the index for the sample report with an example of how a quality related question could be answered using the indexing. After the demonstration, they health system key informants were then asked to comment on: the novelty of the innovation, the relevance of the innovation, and their likelihood of seeking out an EPC report when they were involved in quality or safety related issues in their health-system. Finally, we asked them for suggestions on making the indexing more effective or more efficient.

All of the key informants validated that the length of the reports make it time consuming to read and difficult to parse out the data that they need. They liked the idea of having a table that allows them to see where information relevant to a certain quality measure is located in the report and really liked the ability to hyperlink to that spot to be able to rapidly assess it. They still thought that having an identified quality measure with so many page numbers identified after it still made it more time consuming than they might like. They suggested that the parts of the report that is most informative of the quality measure or has the greatest data density be denoted. Through further discussion we considered either bolding the most relevant pages or using a three color option with green for most relevant, yellow for moderately relevant, and red for distantly relevant. Upon subsequent discussion with the other EPC and AHRQ members in our working group, we opted for bolding the most relevant pages for two reasons. First, to allow it to be read in black font which would result from printing a report on a regular printer and secondly because the nature of the question being asked by the health system could determine whether a portion of the report was fully or moderately relevant. In this latter case, making it two categories (most or moderate) instead of one (more relevant) might lead to members of a health-system disregarding a report that has relevant information because of our determinations. We also expanded our legend to more explicitly inform readers how they could use it to rapidly identify and find information relevant to specific quality measures.

In the phase two assessment, we used the two exercise scenarios and three query questions described in the methods above and included in Appendix A. We first piloted the scenarios with our physician and pharmacists in the research group. It took them between 52 and 60 percent less time to find the correct answers with quality measure indexing than in the absence of such indexing (Table 1). We then provided it to our health-system representatives from a moderately sized community health system (Hartford Healthcare) and a small rural academic health system (UConn Health), respectively. Again, correct answers were found in both scenarios. It took our health-system participants 68 to 82 percent less time to find quality measure information (an average of 7.2 minutes less) when the hyperlinked quality measure indexing tables were available (Table 1). In the qualitative portion of the assessment which was only given to our health-system participants, they both stated they rarely used EPC reports, they both found the 
quality measure index tables very easy to use, and one was somewhat likely and the other very likely to use the reports in the future if they had enhanced quality measure tables available.

Table 1. Time required to find quality measure information in the urinary incontinence report

\begin{tabular}{|l|l|l|l|l|}
\hline Participants & $\begin{array}{l}\text { Time to Find } \\
\text { Answer in } \\
\text { Scenario 1 } \\
\text { without } \\
\text { Enhancement }\end{array}$ & $\begin{array}{l}\text { Time to Find } \\
\text { Answer in } \\
\text { Scenario 1 } \\
\text { with } \\
\text { Enhancement }\end{array}$ & $\begin{array}{l}\text { Time to Find } \\
\text { Answer in } \\
\text { Scenario 2 } \\
\text { without } \\
\text { Enhancement }\end{array}$ & $\begin{array}{l}\text { Time to Find } \\
\text { Answer in } \\
\text { Scenario 2 with } \\
\text { Enhancement }\end{array}$ \\
\hline \hline $\begin{array}{l}\text { Pharmacy } \\
\text { Student/Medical } \\
\text { Fellow 1 }\end{array}$ & $12 \mathrm{~min}$ & $5 \mathrm{~min}$ & $7 \mathrm{~min}$ & $1 \mathrm{~min}$ \\
\hline $\begin{array}{l}\text { Pharmacy } \\
\text { Student/Medical } \\
\text { Fellow 2 }\end{array}$ & $20 \mathrm{~min}$ & $10 \mathrm{~min}$ & $15 \mathrm{~min}$ & $10 \mathrm{~min}$ \\
\hline $\begin{array}{l}\text { Pharmacy } \\
\text { Student/Medical } \\
\text { Fellow 3 }\end{array}$ & $15 \mathrm{~min}$ & $4 \mathrm{~min}$ & $3 \mathrm{~min}$ & $1 \mathrm{~min}$ \\
\hline $\begin{array}{l}\text { Health-System } \\
\text { Representative 1 }\end{array}$ & $9 \mathrm{~min}$ & $0.75 \mathrm{~min}$ & $6 \mathrm{~min}$ & $0.5 \mathrm{~min}$ \\
\hline $\begin{array}{l}\text { Health-System } \\
\text { Representative 2 }\end{array}$ & $12 \mathrm{~min}$ & $3 \mathrm{~min}$ & $11 \mathrm{~min}$ & $5 \mathrm{~min}$ \\
\hline
\end{tabular}

Note: While the participants are described by name in the text, we maintain anonymity of responses.

\section{Discussion}

\section{Utility and Application for Other Health Systems}

We believe that this report enhancement, the inclusion of quality measure tables hyperlinked to the pages of the executive summaries where those quality measures are addressed, could be a health-system "Rosetta Stone”. It would allow the in depth reports to continue to be data and text rich for payor and guideline developers but to allow health systems who are interested in rapidly identifying quality data to do so in these reports. All of the health-system representatives identified the length of reports to be a barrier to using them in their decision-making and they all felt that the quality measure index was an approach that enhanced usability. When we posed two scenarios that were geared towards questions a health-system may have, we found that: there was a 68 to 82 percent reduction in the time it took our health-system representatives to find the appropriate information, the quality measure tables were very easy to use, and it made the representatives somewhat or very likely to use EPC reports in the future. We are confident that once EPCs are proficient at finding quality measures and creating the tables that the entire process would take approximately 30 to 50 hours of time and completed by any team members who were involved in the project and understand the topic area.

We did not have an extensive number of health systems in our pilot project but we did have insight from a large academic, moderate-sized community, and small rural health-system. We also received feedback from physicians, pharmacists, and a nurse. This enhances our confidence that this enhancement could be applicable to many types of health systems regardless of their size or complexity.

We did not assess the value of the two scenarios in helping the health systems key personnel identify how the reports are useful to their roles in their health systems. Quality measure deficiencies identified in a health-system usually requires a system-wide action (educational 
program, order entry note, guideline, or protocol). It is at this step when the data from the EPC reports would be most salient. If AHRQ was to adopt this enhancement, the education for health systems might include scenarios such as this to help them see the value of quality measure indexing.

\section{Lessons Learned and Applicability for Other EPC Reports}

It took a while for our group to understand the topic area and the Urinary Incontinence report before we were able to begin identifying and linking quality measures. This suggests that having EPCs familiar with their own report be responsible for identifying the quality measures and creating the hyperlinked tables rather than having an outside entity linking across reports. However, this will require methods agreeable across EPCs as to the process of determining which quality measures fit and how to hyperlink them within a report. It is important that more than one person was involved in determining whether a quality measure truly fits or not. We chose to have one person be the initial creator of the tables and another person to verify them. However, with greater familiarity, we might not need to have duplication for this function. Any disagreement was handled through discussion and we believe that this process worked well and led to an enhanced report.

The number and type of quality measures varies greatly across disease states or interventions. This undoubtedly means that the value of quality measure indexing may be heterogeneous across topics. It may not make sense to index some reports at all but that is beyond the scope of our project.

The creation of the quality measure tables and hyperlinking to the reports was well received by health systems but they want a further refinement; having the EPCs identify the pages where the most relevant information could likely be found. We chose to do this by bolding those page numbers in our quality measure table. We bolded what we deemed most relevant or pages containing the greatest density of information germane to that quality measure. This underscores the value of early health-system engagement and iterative improvements in report enhancements of any kind. We are indebted to all of our health-system participants and the members of our research group who piloted the innovation.

The NQMC contains a treasure-trove of information on quality measures from various organizations and would make the identification and specification of these measures very efficient. Unfortunately, the NQMC is not being updated for all measures, including urinary incontinence. As such, we had to perform a more comprehensive search to find quality measures, a process that can be emulated by EPCs in other projects regardless of the continuation of the NQMC in the future.

\section{Conclusions}

The creation of supplemental tables that lead to rapid identification of quality measures covered within a report, the page numbers where those quality measure are addressed in the executive summary, and the pages that are likely most informative to health systems interested in this quality measure can enhance the usability of the report by health systems. It could be an inexpensive and efficient way to improve the usability of reports by this important group of stakeholders in the health care system. We estimate that it would take approximately 30 to 50 hours of effort to create this enhancement in projects of moderate to large size and can be done by any of the EPC team members who were involved in completing the project originally. 


\section{References}

1. White CM, Sanders-Schmidler GD, Butler M, et al. Understanding health systems' use of and need for evidence to inform decisionmaking. Agency for Healthcare Research and Quality (US); 2017 Oct. Report 17(18)-EHC035-EF. Rockville, MD PMID 29611913. 


\section{Abbreviations and Acronyms}

AHRQ

EPC
Agency for Healthcare Research and Quality

Evidence-based Practice Center 


\section{Appendix A. Sample Tables for EPC Reports With Exercise and Questions for Key Informants}

Table A-1. Quality measures addressed in the urinary incontinence report

\begin{tabular}{|c|c|c|c|c|c|}
\hline QM\# & Title & $\begin{array}{l}\text { Developerl } \\
\text { Steward }\end{array}$ & $\begin{array}{l}\text { Measure } \\
\text { Type }\end{array}$ & $\begin{array}{l}\text { Quality Program } \\
\text { Utilization }\end{array}$ & KQ\# \\
\hline 1 & $\begin{array}{l}\text { (Not available) } \\
\text { Percentage of female } \\
\text { patients aged } 65 \text { years } \\
\text { and older with a } \\
\text { diagnosis of urinary } \\
\text { incontinence who were } \\
\text { prescribed a medication } \\
\text { to treat the urinary } \\
\text { incontinence who had a } \\
\text { trial of behavioral } \\
\text { therapy documented } \\
(\mathrm{N} / \mathrm{A}) \text {. }\end{array}$ & $\begin{array}{l}\text { AGS } \\
\text { AMA-PCPI } \\
\text { NCQA }\end{array}$ & Process & None & $1,3-4$ \\
\hline 2 & $\begin{array}{l}\text { (AUGS16) Percentage } \\
\text { of patients who have } \\
\text { been offered non- } \\
\text { surgical treatment } \\
\text { (conservative } \\
\text { management) of } \\
\text { urgency urinary } \\
\text { incontinence prior to } \\
\text { surgical intervention. } \\
\text { (HMIS=005095) }\end{array}$ & AUGS & Process & $\begin{array}{l}\text { AQUIRE (CMS- } \\
\text { Approved } \\
\text { Qualified Clinical } \\
\text { Data Registry) }\end{array}$ & $1-4$ \\
\hline 3 & $\begin{array}{l}\text { (AUGS17) Percentage } \\
\text { of obese patients having } \\
\text { documented weight loss } \\
\text { counseling prior to } \\
\text { undergoing anti-urinary } \\
\text { incontinence } \\
\text { procedures. } \\
\text { (HMIS }=004252)\end{array}$ & AUGS & Process & $\begin{array}{l}\text { AQUIRE (CMS- } \\
\text { Approved } \\
\text { Qualified Clinical } \\
\text { Data Registry }\end{array}$ & 1,4 \\
\hline 4 & $\begin{array}{l}\text { (NQMC\#09647) } \\
\text { Percentage of patients } \\
\text { being treated for UI that } \\
\text { show } \\
\text { resolution/improvement } \\
\text { of signs and symptoms } \\
\text { of UI }\end{array}$ & AMDA & Outcome & None & $1-4$ \\
\hline
\end{tabular}




\begin{tabular}{|c|c|c|c|c|c|}
\hline QM\# & Title & $\begin{array}{l}\text { Developerl } \\
\text { Steward }\end{array}$ & $\begin{array}{l}\text { Measure } \\
\text { Type }\end{array}$ & $\begin{array}{l}\text { Quality Program } \\
\text { Utilization }\end{array}$ & KQ\# \\
\hline $\begin{array}{l}\text { QM\# } \\
\text { (continue } \\
\text { d) }\end{array}$ & Title (continued) & $\begin{array}{l}\text { Developer/ } \\
\text { Steward } \\
\text { (continued) }\end{array}$ & $\begin{array}{l}\text { Measure } \\
\text { Type } \\
\text { (continued } \\
\text { ) }\end{array}$ & $\begin{array}{l}\text { Quality Program } \\
\text { Utilization } \\
\text { (continued) }\end{array}$ & $\begin{array}{l}\text { KQ\# } \\
\text { (continu } \\
\text { ed) }\end{array}$ \\
\hline 5 & $\begin{array}{l}\text { (NQMC\#09639) } \\
\text { Percentage of patients } \\
\text { with UI who are } \\
\text { appropriate for a toileting } \\
\text { program that have one. }\end{array}$ & AMDA & Process & None & $1,3-4$ \\
\hline 6 & $\begin{array}{l}\text { (NQMC\#09644) } \\
\text { Percentage of patients } \\
\text { who are being monitored } \\
\text { for side effects of } \\
\text { medications prescribed } \\
\text { for the treatment of UI. }\end{array}$ & AMDA & Process & None & $2-4$ \\
\hline 7 & $\begin{array}{l}\text { (NQMC\#09649) } \\
\text { Percentage of patients } \\
\text { with UI who have had } \\
\text { nonessential } \\
\text { anticholinergic } \\
\text { medications } \\
\text { discontinued to reduce } \\
\text { the overall } \\
\text { anticholinergic load. }\end{array}$ & AMDA & Process & None & $2-4$ \\
\hline 8 & $\begin{array}{l}\text { (NQMC\#09633) } \\
\text { Percentage of patients } \\
\text { assessed for modifiable } \\
\text { causes of UI so that } \\
\text { interventions may be } \\
\text { targeted to those factors. }\end{array}$ & AMDA & Process & None & $1-4$ \\
\hline 9 & $\begin{array}{l}\text { (NQMC\#09640) } \\
\text { Percentage of patients } \\
\text { who have failed on } \\
\text { nonpharmacologic } \\
\text { interventions and are } \\
\text { then evaluated for } \\
\text { pharmacologic } \\
\text { treatment. }\end{array}$ & AMDA & Process & None & $1-4$ \\
\hline
\end{tabular}

AGS = American Geriatrics Society; AMA-PCPI = American Medical Association Physician Consortium for Performance Improvement; AMDA = American Medical Director's Association; AUGS = American UroGynegologic Society; CMS = Centers for Medicare \& Medicaid Services; KQ = Key Question; NCQA = National Committee for Quality Assurance; NQMC = National Quality Measure Clearinghouse; QM = Quality Measure; UI = urinary incontinence 
Table A-2. Index of where information on urinary incontinence quality measures can be found in the text

\begin{tabular}{|c|c|}
\hline QM \# & Pages indexed \\
\hline 1 & 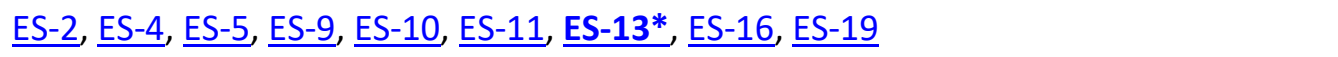 \\
\hline 2 & 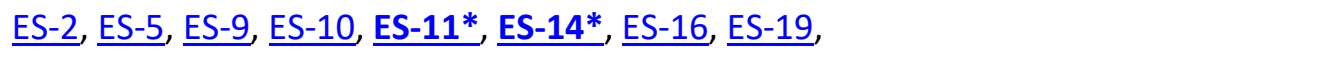 \\
\hline 3 & $\underline{\text { ES-4 }}$ ES-5, ES-9, ES-10, ES-11* $\underline{\text { ES-14* }}, \underline{\text { ES-16, ES-19 }}$ \\
\hline 4 & 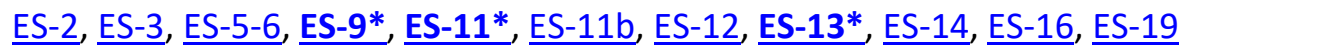 \\
\hline 5 & 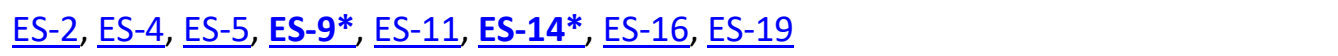 \\
\hline 6 & 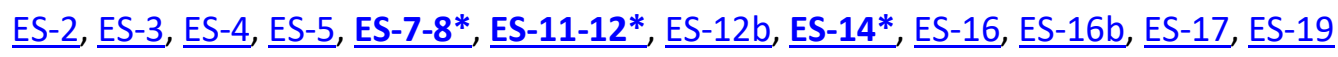 \\
\hline 7 & $\underline{\text { ES-2, }} \underline{\text { ES-5, ES-6* }}, \underline{\text { ES-14* }}, \underline{\text { ES-19 }}$ \\
\hline 8 & $\underline{\text { ES-2, }} \underline{\text { ES-5, ES-9, }} \underline{\underline{E S}-11 *}, \underline{\text { ES-14* }}, \underline{\text { ES-16, ES-19 }}$ \\
\hline 9 & $\underline{\text { ES-2}}, \underline{E S-4}, \underline{E S-5}, \underline{E S-9}, \underline{E S-11 *}, \underline{E S-13 *}, \underline{E S-16}, \underline{E S-19}$ \\
\hline
\end{tabular}

Note: Each page number starts with ES for Executive Summary followed by the number. The bolded and asterisked page numbers will generally contain the greatest amount or most pertinent information germane to that quality measure and is an efficient place to start. For information on the definitions of the quality measures and which organization of society endorses it, please see Appendix J, Table 1.

*These page numbers will generally contain the greatest amount or most pertinent information germane to that quality measure and is an efficient place to start.

Exercises for Key Informants:

\begin{tabular}{|l|l|l|l|l|l|}
\hline QM\# & Title & $\begin{array}{l}\text { Developerl } \\
\text { Steward }\end{array}$ & $\begin{array}{l}\text { Measure } \\
\text { Type }\end{array}$ & $\begin{array}{l}\text { Quality } \\
\text { Program } \\
\text { Utilization }\end{array}$ & KQ\# \\
\hline 6 & $\begin{array}{l}\text { (NQMC\#09644) Percentage of patients } \\
\text { who are being monitored for side effects of } \\
\text { medications prescribed for the treatment of } \\
\text { Ul. }\end{array}$ & AMDA & Process & None & $2-4$ \\
\hline
\end{tabular}

Scenario 1: Your health system employs many treatment strategies for UI with varying risk of side effects. Your hospital has 80 percent of patients being appropriately monitored for side effects while your comparator health systems have 93 percent appropriate monitoring for the quality measure identified by NQMC \# 09644, detailed above. Studies have shown that limiting side effects is a high priority for patients, while physicians place a higher priority on benefits of treatment. Your quality team wants to create a guideline that can identify the main adverse events associated with UI drugs so that clinicians can be reminded to look for them. Use the executive summary of the EPC report without the hyperlinked quality measure index to find the answer in the executive summary and record how long it takes. Then repeat the process using the hyperlinked index and record the time it took to find the answer using the quality measure tool. 
Answer: "The highest rate of serious adverse events was reported with periurethral bulking agents (4.7\%) (moderate SoE).” On page ES-7

\begin{tabular}{|l|l|}
\hline Using report without indexing & Using indexing to find the answer \\
\hline Time to find answer: & Time to find answer: \\
\hline The answer found: & The answer found: \\
& \\
\hline
\end{tabular}

\begin{tabular}{|l|l|l|l|l|l|}
\hline QM\# & Title & $\begin{array}{l}\text { Developerl } \\
\text { Steward }\end{array}$ & $\begin{array}{l}\text { Measure } \\
\text { Type }\end{array}$ & $\begin{array}{l}\text { Quality } \\
\text { Program } \\
\text { Utilization }\end{array}$ & KQ\# \\
\hline 8 & $\begin{array}{l}\text { (NQMC\#09633) Percentage of patients } \\
\text { assessed for modifiable causes of UI so } \\
\text { that interventions may be targeted to those } \\
\text { factors. }\end{array}$ & AMDA & Process & None & $1-4$ \\
\hline
\end{tabular}

Scenario 2: According to guidelines, modifiable UI causes should be identified and then first treated with behavioral therapies before pharmacologic therapies are tried or added. In your health system, 55 percent of patients are being assessed for modifiable causes and only 35 percent are being given behavioral therapies as the first line treatment for UI versus your comparator hospitals which are at 75 percent and 60 percent, respectively. After consultation with your clinicians, the quality improvement team believes that if clinicians were more aware of behavioral therapies that were effective at treating modifiable causes of UI, more patients would be assessed and then prescribed behavioral therapy. As such, you identify room for improvement in your health system regarding NQMC \#09633 which is detailed above. Use the executive summary of the EPC report to find the cure rate in women from behavioral therapy alone and record how much time it takes to find this answer. Then repeat the process using the hyperlinked index and record the time it took the find the answer using the tool and record the time.

Answer: 30.7\%, 95\% CI (23.9, 38.5) on page ES-11

\begin{tabular}{|l|l|}
\hline Using report without indexing & Using indexing to find the answer \\
\hline Time to find answer: & Time to find answer: \\
The answer found: & The answer found: \\
& \\
\hline
\end{tabular}




\section{Questions for Key Informants:}

How often do you use an EPC report to answer a question related to how to improve your health system's standing for a quality measure?

\begin{tabular}{|l|l|l|l|l|}
\hline Rarely & Somewhat rarely & $\begin{array}{l}\text { Neither rarely nor } \\
\text { often }\end{array}$ & Somewhat often & Often \\
\hline
\end{tabular}

How would you rate the user-friendliness of the quality measure indexing tool?

\begin{tabular}{|l|l|l|l|l|}
\hline $\begin{array}{l}\text { Very difficult to } \\
\text { use }\end{array}$ & Somewhat difficult & $\begin{array}{l}\text { Neither easy nor } \\
\text { difficult }\end{array}$ & Somewhat easy & Very easy to use \\
\hline
\end{tabular}

How likely would you be to use an indexed report like this one in the future to answer a question related to how to improve your health system's standing for a quality measure?

\begin{tabular}{|l|l|l|l|l|}
\hline Not likely at all & Somewhat unlikely & Neutral & Somewhat likely & Very likely
\end{tabular}

